\title{
Self-stigma, group identification, perceived legitimacy of discrimination and mental health service use
}

Nicolas Rüsch, Patrick W. Corrigan, Abigail Wassel, Patrick Michaels, Jonathon E. Larson, Manfred Olschewski, Sandra Wilkniss and Karen Batia

\section{Summary}

Stigma may interfere with mental health service use. We measured self-stigma and stigma-related cognitions (group identification and perceived legitimacy of discrimination) at baseline in 85 people with schizophrenia, schizoaffective or affective disorders. After 6 months, 75 (88\%) had reported use of mental health services. Controlling for baseline psychopathology, perceived stigma and diagnosis, low perceived legitimacy of discrimination predicted use of counselling/ psychotherapy. Strong group identification was associated with participation in mutual-help groups. More self-stigma predicted psychiatric hospitalisation. Cognitive indicators of stigma resilience may predict out-patient service use, whereas selfstigma may increase the risk of psychiatric hospitalisation.

\section{Declaration of interest}

None.
It has been claimed ${ }^{1}$ that stigma is a major barrier to mental health service use and explains, among other factors such as accessibility and quality of services, why many people choose not to participate in treatment. However, empirical support for this assertion is scarce. ${ }^{2}$ We therefore examined the impact of self-stigma and stigma-related cognitions on service use. In this context, perceived stigma refers to the level of stigma people with mental illness observe in society (e.g. 'The public thinks people with mental illness are stupid'); self-stigma implies internalisation of public stigma, resulting in low self-esteem (e.g. 'I have a mental illness and therefore I am stupid').

As baseline predictors of service use over 6 months, we assessed self-stigma, the level of perceived stigma and two key stigma-related cognitions that indicate resilience to stigma (low perceived legitimacy of discrimination and strong identification with the group of people with mental illness). ${ }^{3,4}$ Assuming that stigma may affect the use of various services differently, we studied three services: in addition to counselling/psychotherapy, we chose a more empowering (mutual-help/peer-support groups run by consumers) $v$. a more disempowering (psychiatric admission) service, and a conservative design, controlling for baseline psychopathology.

\section{Method}

Eighty-five participants with mental illness were recruited from centres offering out-patient mental health services in the Chicago area. ${ }^{5}$ Of these, $75(88 \%)$ completed the follow-up assessment after 6 months, and 10 could not be contacted or were not willing to participate. At follow-up, participants reported whether they had used individual psychotherapy/counselling, mutual-help/ peer-support groups or psychiatric hospitalisation. Psychotherapy/ counselling was available in community clinics or day programmes and was often limited in number depending on funding sources.

All participants gave written informed consent and the study was approved by the institutional review boards of the Illinois Institute of Technology and collaborating organisations. Mean (s.d.) age of the 75 participants was 44.3 (9.8) years and 69\% were male; mean (s.d.) years of education was 13.6 (2.3). Over half (56\%) were African American and a third (35\%) were White; a few reported Hispanic/Latino (5\%) or mixed/other (4\%) ethnicities. Axis I diagnoses were made using the Mini International Neuropsychiatric Interview. ${ }^{6}$ Overall, 18 participants (24\%) had schizophrenia, 21 (28\%) had schizoaffective, 27 (36\%) had bipolar I or II, and $9(12 \%)$ had recurrent unipolar major depressive disorder. Also, 32 (43\%) had comorbid current alcohol or substance use disorder or dependence. On average, participants were first diagnosed about 14.1 (s.d.=9.7) years ago and had been admitted to psychiatric institutions about nine times (mean 8.8, s.d. $=13.5$ ).

We measured self-stigma on the 10-item self-esteem decrement subscale of the Self-Stigma of Mental Illness Scale ${ }^{7}(\alpha=0.88)$. The level of stigma participants perceived in society was assessed using the 12-item Perceived Devaluation-Discrimination Questionnaire ${ }^{8}$ $(\alpha=0.85)$. Perceived legitimacy of discrimination is defined as an individual's perception that their ingroup's lower status in the social hierarchy is fair and legitimate. It was assessed with three items adapted from Schmader $e^{a}$ al' (e.g. 'Do you think it is justified that people without a mental disorder have a higher status than people with a mental disorder?') $(\alpha=0.82)$. Identification with the group of people with mental illness was conceptualised by five items adapted from Jetten et $a l^{10}$ (e.g. 'I feel strong ties with the group of people with mental illness') $(\alpha=0.85)$. General psychopathology was assessed using a short 9-item version of the Symptom Check List-Revised ${ }^{11}(\alpha=0.82)$. For all scales, higher scores represented higher levels of the measured constructs.

\section{Results}

For both psychotherapy/counselling and mutual-help/peersupport groups, we found a bimodal distribution: a large majority of participants had either used the service continuously over 6 months or not at all. A small minority had used the service either only once or for less than 6 months. For logistic regressions, we categorised the use of each service as a dichotomous dependent variable (using the service not at all/only once $v$. for 1-6 months). Among 75 participants at follow-up, 52 (69\%) had used individual counselling/psychotherapy, and $23(31 \%)$ had used this service once or not at all. Mutual-help/peer-support groups were used by $35(47 \%)$, and $40(53 \%)$ had used them only once or not at all. Overall, 16 participants (21\%) were admitted to psychiatric hospitals over the follow-up period, whereas 59 (79\%) were not.

Controlling for baseline levels of perceived stigma and psychopathology, low perceived legitimacy of discrimination, but not self-stigma or group identification, predicted use of counselling/ psychotherapy (Table 1). Participation in mutual-help/peersupport groups, on the other hand, was predicted by strong group 


\begin{tabular}{|c|c|c|c|c|c|}
\hline Dependent variable & Independent variables & B & Wald & $P$ & Nagelkerke $R$ \\
\hline Counselling/psychotherapy a & $\begin{array}{l}\text { Group identification } \\
\text { Perceived legitimacy of discrimination } \\
\text { Self-stigma }^{\mathrm{b}} \\
\text { Perceived stigma }^{\mathrm{c}} \\
\text { General psychopathology }^{\mathrm{d}}\end{array}$ & $\begin{array}{r}0.31 \\
-0.64 \\
0.04 \\
-0.01 \\
-0.26\end{array}$ & $\begin{array}{l}2.04 \\
6.76 \\
2.08 \\
0.001 \\
0.52\end{array}$ & $\begin{array}{l}0.15 \\
0.009 \\
0.15 \\
0.98 \\
0.47\end{array}$ & 0.26 \\
\hline Mutual-help/peer-support groups ${ }^{a}$ & $\begin{array}{l}\text { Group identification } \\
\text { Perceived legitimacy of discrimination } \\
\text { Self-stigma }^{\mathrm{b}} \\
\text { Perceived stigma } \\
\text { General psychopathology }^{\mathrm{d}}\end{array}$ & $\begin{array}{r}0.90 \\
0.17 \\
0.03 \\
-0.55 \\
-0.53\end{array}$ & $\begin{array}{r}10.81 \\
0.56 \\
1.68 \\
1.81 \\
2.26\end{array}$ & $\begin{array}{l}0.001 \\
0.45 \\
0.20 \\
0.18 \\
0.13\end{array}$ & 0.35 \\
\hline Psychiatric hospitalisation ${ }^{\mathrm{e}}$ & $\begin{array}{l}\text { Group identification } \\
\text { Perceived legitimacy of discrimination } \\
\text { Self-stigma }^{\mathrm{b}} \\
\text { Perceived stigma }^{\mathrm{c}} \\
\text { General psychopathology }^{\mathrm{d}}\end{array}$ & $\begin{array}{r}-0.43 \\
-0.56 \\
0.08 \\
-0.71 \\
-0.20\end{array}$ & $\begin{array}{l}3.09 \\
3.27 \\
6.73 \\
1.96 \\
0.26\end{array}$ & $\begin{array}{l}0.08 \\
0.07 \\
0.009 \\
0.16 \\
0.61\end{array}$ & 0.24 \\
\hline \multicolumn{6}{|c|}{$\begin{array}{l}\text { a. Service use over } 6 \text { months, never/only once (coded as 0) } v \text {. continuously/part-time (coded as } 1 \text { ). } \\
\text { b. Self-esteem decrement due to self-stigma ( (self-Stigma of Mental Illness scale). } \\
\text { c. Perceived Devaluation-Discrimination Questionnaire. } \\
\text { d. Short version of the Symptom Checklist-Revised.1 } \\
\text { e. Psychiatric hospitalisation: no (coded as } 0 \text { ) v. yes (coded as 1) }\end{array}$} \\
\hline
\end{tabular}

identification. High self-stigma at baseline predicted psychiatric hospitalisation, independent of perceived stigma and psychopathology.

We then repeated the regression analyses to control for the possible confound of diagnosis (schizophrenia/schizoaffective disorder $v$. bipolar disorder/unipolar depression; and presence $v$. absence of a current substance-related disorder as dummy-coded variables). Diagnoses were not significant predictors in any of the regressions (all $P>0.40$ ), and all previously significant predictors remained significant.

\section{Discussion}

We found evidence that self-stigma and stigma-related cognitions predict service use among people with serious and chronic mental illness, independent of baseline psychopathology, diagnosis and the level of perceived stigma. Cognitions associated with resilience to stigma (rejecting stigma as unfair; strong group identification) $)^{3,4}$ may facilitate use of out-patient services and be more relevant to help-seeking than the level of perceived stigma per se. Increased self-stigma, on the other hand, could be associated with reduced willingness or ability to seek help, possibly leading to decreased coping resources and thus to psychiatric hospitalisation as a last resort. The time lag between baseline assessment of psychopathological symptoms and subsequent hospitalisation may explain the lack of association between the two.

Limitations of our study should be considered. First, we did not collect information on service use from sources other than service users, and dichotomous dependent variables limited the power of our analyses. Second, despite our longitudinal data, firm conclusions on causality cannot be drawn because treatment participation before baseline assessment may have influenced stigma-related predictor variables. Third, our conclusions are limited to people with serious and chronic mental illness who already participate in mental health services. Finally, stigmarelated variables, accessibility, quality and use of services should be investigated in different healthcare systems internationally.

Stigma-related factors appear to affect mental health service use. High self-stigma could be a risk factor for psychiatric hospitalisation, whereas strong group identification may encourage people with mental illness to turn to peers for mutual help, thus increasing empowerment. Research should investigate how initiatives meant to reduce self-stigma, public stigma and structural discrimination can facilitate help-seeking.

\section{Funding}

Our work was supported by a Marie Curie Outgoing International Fellowship of the EU to N.R. and by funding from the NIAA, NIMH and the Fogarty International Center to P.W.C.

Nicolas Rüsch, MD, Patrick W. Corrigan, PsyD, Abigail Wassel, BA, Patrick Michaels, BSC, Jonathon E. Larson, EdD, Illinois Institute of Technology, Chicago; Manfred Olschewski, MSc, University of Freiburg, Germany; Sandra Wilkniss, Manfred Olschewski, MSC, University of Freiburg, Germany; Sandra Wilkniss,
PhD, Thresholds Institute, Chicago; Karen Batia, PhD, Heartland Alliance for Human Needs \& Human Rights, Chicago, USA

Correspondence: Nicolas Rüsch, Department of Psychiatry and Psychotherapy, University of Freiburg, Hauptstr. 5, 79104 Freiburg, Germany. Email:

nicolas.ruesch@uniklinik-freiburg.de

First received 10 Apr 2009, final revision 10 Jul 2009, accepted 21 Aug 2009

\section{References}

1 Corrigan PW. How stigma interferes with mental health care. Am Psychol 2004; 59: 614-25.

2 Schomerus G, Angermeyer MC. Stigma and its impact on help-seeking for mental disorders: what do we know? Epidemiol Psichiatr Soc 2008; 17: 31-7

3 Watson AC, Corrigan PW, Larson JE, Sells M. Self-stigma in people with mental illness. Schizophr Bull 2007; 33: 1312-8.

4 Rüsch N, Lieb K, Bohus M, Corrigan PW. Self-stigma, empowerment, and perceived legitimacy of discrimination among women with mental illness. Psychiatr Serv 2006; 57: 399-402.

5 Rüsch N, Corrigan PW, Wassel A, Michaels P, Olschewski M, Wilkniss S, et al. A stress-coping model of mental illness stigma: I. Predictors of cognitive stress appraisal. Schizophr Res 2009; 110: 59-64.

6 Sheehan DV, Lecrubier $\mathrm{Y}$, Sheehan $\mathrm{KH}$, Amorim P, Janavs J, Weiller E, et al. The Mini-International Neuropsychiatric Interview (M.I.N.I.): the development and validation of a structured diagnostic psychiatric interview for DSM-IV and ICD-10. J Clin Psychiatry 1998; 59 (suppl 20): 22-33.

7 Corrigan PW, Watson AC, Barr L. The self-stigma of mental illness: implications for self-esteem and self-efficacy. J Soc Clin Psychol 2006; 25: 875-84.

8 Link BG. Understanding labeling effects in the area of mental disorders: an assessment of the effects of expectations of rejection. Am Sociol Rev 1987; 52: 96-112.

9 Schmader T, Major B, Eccleston CP, McCoy SK. Devaluing domains in response to threatening intergroup comparisons: perceived legitimacy and the status value asymmetry. J Pers Soc Psychol 2001; 80: 782-96.

10 Jetten J, Branscombe NR, Schmitt MT, Spears R. Rebels with a cause: group identification as a response to perceived discrimination from the mainstream. Pers Soc Psychol Bull 2001; 27: 1204-13.

11 Klaghofer R, Brähler E. Konstruktion und teststatistische Prüfung einer Kurzform der SCL-90-R [Construction and statistical evaluation of a short version of the SCL-90-R]. Z Klin Psychol Psychiatr Psychother 2001; 49: $115-24$. 